\title{
TEATRO NO ENSINO SUPERIOR CATARINENSE: REFLEXÖES NA PERSPECTIVA BAKHTINIANA
}

\section{Jean Carlos Gonçalves}

Bacharel e Licenciado em Teatro-Interpretaçāo - FURB. Mestre em Educaçāo - FURB. Doutor em Educaçāo - UFPR. Professor da área de Práticas Teatrais. na Graduaçāo em Produçāo Cênica da UFPR. 
RESUMO: Este estudo teve como objetivo refletir sobre o ensino superior em Teatro no estado de Santa Catarina, a partir dos discursos institucionais das universidades sobre suas graduações. Foram analisadas as materialidades linguísticas encontradas nas páginas de apresentação dos cursos na internet. As textualidades originaram quadros diagnósticos a partir dos quais foi possível realizar um estudo de cunho enunciativo, ancorado na perspectiva bakhtiniana de análise. Os resultados apontaram para movimentos de alteridade na história do ensino superior catarinense na área de Teatro, permitindo a compreensão de tal objeto investigativo como um campo de conhecimento em permanente construção, no qual estão em jogo diferentes possibilidades e expectativas de formação superior em Teatro.

PALAVRAS-CHAVE: Teatro; Ensino Superior; Santa Catarina; Círculo de Bakhtin.

\begin{abstract}
This study aimed to reflect on higher education in theater in the state of Santa Catarina, from the institutional discourse of universities about their courses. We analyzed the linguistic material found in the pages of presentation of courses on the Internet. from The textualities it was possible to conduct a study of discursive nature, anchored in the perspective of Bakhtinian analysis. Results showed movements of alterity in the history of higher education in theater of Santa Catarina, allowing the understanding of such an object as an investigative field of knowledge in permanent construction, which are in different game possibilities and expectations of higher education in theater.
\end{abstract}

KEYWORDS: Theater; Higher Education; Santa Catarina; Bakhtin's Circle.

\title{
APRESENTAÇÃO
}

Nesse espaço de discussão proponho algumas reflexões relacionadas ao ensino superior na área de Artes Cênicas no ambiente acadêmico catarinense. Disserto sobre o surgimento dos quatro cursos de Teatro no estado, a inserção regional de cada um deles e as diferentes trajetórias das habilitações de formação. O objetivo do trabalho é refletir sobre a história atual do ensino superior catarinense, na perspectiva analítica dos estudos enunciativos do Círculo de Bakhtin. A materialidade linguística (corpus) é composta de informações contidas nas páginas da internet dos quatro cursos superiores em Teatro de Santa Catarina. 
Antes da análise, porém, abordo a concepção de universidade presente no estudo, para então, relacioná-la à prática teatral nesse contexto.

Grêmio, integração entre mestres e estudantes. Esse é o significado sociológico da palavra Universidade (ALMEIDA, 2006). O vocábulo, originado na palavra universum, propõe a totalidade do real, e representa a abertura para a totalidade do ser humano e da compreensão daquilo que o circunda, por meio de um debate constante sobre as verdades e incertezas da vida, a busca pela essência das ciências e pela riqueza e sabedoria do homem.

Com origem histórica no final da Idade Média, entre os séculos XI e XII, o termo universidade, ao longo do seu percurso histórico, foi adquirindo novos sentidos, acompanhando a consolidação das instituições em diferentes lugares e esferas geográficas, até se estabelecerem como locais de construção e produção de conhecimento.

As universidades se distinguem de outras instituições de ensino superior por sua possibilidade de autonomia e sua postura de integração entre ensino, pesquisa e extensão como componentes indissociáveis do ambiente acadêmico. A Constituição da República Federativa do Brasil, de 1988, garante no Art. 207 que "As universidades gozam de autonomia didático-científica, administrativa e de gestão financeira e patrimonial e obedecerão ao princípio de indissociabilidade entre ensino, pesquisa e extensão".

Para o MEC (Ministério da Cultura, Educação e Desporto), o ensino superior no Brasil abrange os cursos de graduação (oferecidos a pessoas que tenham concluído a educação básica, que adentram a universidade por meio de processos seletivos), e os cursos de pós-graduação em níveis de especialização, mestrado e doutorado, e cursos de extensão oferecidos à comunidade.

A LDB, Lei de Diretrizes e Bases da Educação Nacional, prevê que a finalidade da educação superior implica na diplomação de sujeitos em diferentes áreas do conhecimento que, ao se tornarem egressos de seus cursos, estejam aptos a exercer atividades profissionais em diversos setores da sociedade, 
colaborando para a construção do saber nas comunidades onde se inserem (Art. 43, II Lei 9394/96).

A educação superior exerce papel de suma importância ao propor a produção e reelaboração do conhecimento em diversas áreas, pois um dos objetivos primordiais da universidade, segundo Lorgus é

[...] transformar a práxis cotidiana em um exercício axiológico de transformação da realidade, ou seja, a partir do momento em que existe a promoção da educação superior pela universidade, existe uma nova construção de valores que vai culminar em uma prática diferenciada, adequando-a cada vez mais às necessidades do homem (LORGUS, 2009, p. 32).

No estado de Santa Catarina, a primeira instituição de ensino superior foi criada em 1917, em Florianópolis, como Instituto Politécnico. Nos estudos de Almeida (2006), encontram-se dados pertinentes ao surgimento de outros espaços de ensino entre 1940 e 1960, como a Faculdade de Ciências Econômicas, Odontologia e Farmácia, Filosofia, Medicina e Serviço Social que, reunidas em uma única instituição, dão origem à primeira universidade do estado: a UFSC Universidade Federal de Santa Catarina em 1960.

A partir de então, diversas reivindicações para a abertura de outras universidades no território catarinense começam a mover o governo de Celso Ramos no sentido de propiciar condições para tal concretização. Para Hawerroth (1999), o ensino superior tinha como intuito o estabelecimento de uma base sólida para o desenvolvimento econômico e social, incentivando a melhoria na qualidade de vida dos habitantes do estado.

Em 1965, o governo cria a Universidade Para o Desenvolvimento do Estado, a UDESC, a segunda universidade pública de Santa Catarina, com sede em Florianópolis. Desde então, o crescimento de movimentos em prol do ensino superior em outras regiões começa a ser notado por meio de iniciativas de ordem privada e municipal.

Através de lei municipal e em virtude dos primeiros a favor de uma universidade no Vale do Itajaí, é criada a primeira instituição de ensino superior descentralizada na cidade de Blumenau: A FACEB - Faculdade de Ciências 
Econômicas de Blumenau. Já em 1967 são instituídas as Faculdades de Ciências Jurídicas e de Filosofia, Ciências e Letras, que dão origem à FUB - Fundação Universitária de Blumenau, entidade mantenedora dos cursos superiores existentes. Esta, por sua vez, em 1968 viria a se tornar FURB - Fundação Universidade Regional de Blumenau, a primeira universidade localizada fora da capital catarinense.

Seguindo o projeto de descentralização, em 1968 era criada a Fundação Universitária do Oeste de Santa Catarina (FUOC). As necessidades regionais, o sonho e o desejo da comunidade e fatores de ordem econômica, política e social influenciaram para o início da movimentação em Joaçaba em direção à criação de cursos de ensino superior. Esse movimento daria espaço para a criação da UNOESC (Universidade do Oeste Catarinense), o qual hoje é referência na região.

Não pretendo, nesse trabalho, nem é meu objeto de estudo, traçar um panorama histórico e quantitativo do ensino superior catarinense. Mas não posso deixar de situar o fato de que as universidades mencionadas acima e distintamente marcadas por movimentos de pioneirismo e relevância social no estado são as mesmas e as únicas que possuem atualmente cursos superiores na área de Artes Cênicas. São eles:

\begin{tabular}{|l|l|}
\hline UNIVERSIDADE & \multicolumn{1}{c|}{ CURSO } \\
\hline UFSC & Bacharelado em Artes Cênicas, Habilitação em Teatro \\
\hline UDESC & Bacharelado e Licenciatura em Teatro \\
\hline UNOESC & Licenciatura em Artes Cênicas \\
\hline FURB & Bacharelado em Teatro - Interpretação \\
\hline
\end{tabular}

Para compreender melhor o surgimento desses cursos, seu funcionamento, abrangência regional e matrizes conceituais, apresento em forma de síntese organizativa nomeadas de quadros diagnósticos, uma breve reflexão sobre cada curso no contexto das universidades descritas acima, a partir da análise da materialidade linguística presente nas páginas da internet das universidades 
citadas, onde constam informações referentes aos objetivos e alcance dos cursos, habilitações de formação oferecidas, carga horária, turnos de ensino e a situação das disciplinas que tem como foco a prática de montagem de espetáculos teatrais.

Reflito sobre seus objetivos, inserção regional e histórica, utilizando como aporte referencial de análise, os estudos enunciativos na perspectiva bakhtiniana.

\section{UNIVERSIDADE DO ESTADO DE SANTA CATARINA (UDESC)}

\section{Quadro diagnóstico}

(Informações colhidas na página de apresentação do curso na internet em 2010). INSTITUIÇÃO: Universidade do Estado de Santa Catarina NOME DO CURSO: Bacharelado e Licenciatura em Teatro TEXTO DE APRESENTAÇÃO DO CURSO:

Implantado em 10 de abril de 1986, o Departamento de Artes Cênicas oferece atualmente dupla habilitação em Teatro. Qualifica quer profissionais para atuar nas diversas áreas cênicas, quer professores para ministrar essa disciplina.

O curso fomenta a criação e a produção de espetáculos em diferentes expressividades cênicas, assim como forma arte-educadores, pesquisadores e interessados em prosseguir estudos em nível de pós-graduação.

Há em Florianópolis e no Estado, hoje em dia, uma proliferação significativa de espaços na área do ensino de Teatro, fruto do trabalho de ex-alunos do curso. O Departamento está organizado em duas áreas de concentração: Práticas no Ensino e Teatro, com linhas de pesquisa direcionadas às formas interativas do Teatro na escola e na comunidade, e Teoria e Prática do Espetáculo Teatral, com linhas de pesquisa direcionadas à história, crítica e linguagens do espetáculo.

HABILITAÇÃO: Bacharelado e Licenciatura em Teatro.

TITULAÇÃO: Bacharel e Licenciado em Teatro.

CRIAÇÃO: Resolução CONSUNI no 005/86, em 10/04/1986.

INÍCIO DAS ATIVIDADES: Agosto de 1986.

ÚLTIMA ALTERAÇÃO CURRICULAR: Resolução no 008/2008 CONSUNI. 
PERÍODO DE CONCLUSÃO DO CURSO: 9 semestres.

CARGA HORÁRIA OBRIGATÓRIA: 3.906 h/a (sendo 270 h/a em Atividades

Complementares).

VAGAS: 40 vagas anuais.

TURNO: Matutino e Vespertino.

SEMESTRE EM QUE O CURSO É OFERECIDO NO VESTIBULAR:1‥ LOCAL DE FUNCIONAMENTO: Florianópolis.

O curso de Bacharelado e Licenciatura em Teatro da UDESC é o primeiro da área de Artes Cênicas a funcionar em Santa Catarina. No texto de apresentação é possível identificar a abrangência estadual do curso, quando o mesmo defende o fato de ser um agente fomentador da criação e da produção de espetáculos "no Estado". Essa pista linguística permite sinalizar para a heterogeneidade que permeia o ambiente universitário da UDESC, constituído pelos sujeitos que procuram esta universidade, e especificamente este curso. Desde 1986 até 2008, este é o único curso de Artes Cênicas catarinense oferecido em universidade pública, o que aumenta a procura de sujeitos advindos de várias partes do estado. Mesmo a partir de 1995, com a criação de mais um curso superior em Teatro no estado, na Universidade Regional de Blumenau, o curso da UDESC não chega a ficar ameaçado, em virtude de a FURB oferecer uma graduação paga, direcionada, portanto a um público de caráter mais regional do que estadual ou nacional.

O texto ainda aponta para o fato de que os egressos saírem aptos a criar e produzir Teatro no território catarinense, isto é, muitos foram estudar em Florianópolis e voltaram a sua cidade de origem, agora com a titulação e provavelmente com maiores possibilidades de exercício da profissão.

Profissão esta, exercida tanto na docência como na criação artística. Essas textualidades permitem a interpretação de que o curso acredita que seus egressos têm dado uma importante contribuição ao ensino e à propagação do Teatro no estado. Esse discurso se repete, reafirmando a ideia de que é este curso o grande responsável pelo avanço do ensino do Teatro catarinense: Há em Florianópolis, e 
no Estado, hoje em dia, uma proliferação significativa de espaços na área do ensino de teatro, fruto do trabalho de ex-alunos do curso. A partir de 2008 (mesmo ano em que a UFSC inicia o curso de bacharelado em Teatro) é oferecida aos acadêmicos ingressantes uma dupla titulação (bacharelado e licenciatura), mas os traços de constituição do curso como uma licenciatura ainda o marcam e definem os enunciados sobre si. Isto é, mesmo ofertando uma nova habilitação, o curso não tem como negar o que foi e como se constituiu. Assim, a formação de arteeducadores sempre estará imbricada à formação de atores.

Para Bakhtin (2006), os enunciados são frutos da esfera social na qual interagem os sujeitos. Na esfera social e histórica da UDESC, o curso de licenciatura é uma realidade que corrobora para um discurso pela arte-educação, que o faz, hoje, ser referência na formação de professores de Teatro em Santa Catarina.

Ao apresentar as áreas de concentração que constituem o curso, há um primeiro indício de que a dupla habilitação viria a se tornar realidade. A descrição das linhas que compõem as áreas Práticas no Ensino de Teatro e Teoria e Prática do Espetáculo Teatral são indicadores de que há professores e alunos mais interessados no teatro-educação e outros no Teatro como produção espetacular e criação cênica, isto é, como atores, diretores, cenógrafos, etc. As discussões possíveis são: o professor de Teatro já não é ator, diretor, cenógrafo? O título de bacharel, além do de licenciado, garante ao artista uma especificidade de formação? A criação de um bacharelado no ano de início de outro curso de mesma titulação e na mesma cidade, em universidade pública, seria uma pista de análise para pensar o mecanismo de alteridade e de constituição curricular na esfera acadêmica?

Não é meu objeto de estudo perseguir as respostas ou refletir sobre essas questões, visto que meu interesse está voltado a uma apresentação das universidades e dos cursos em Artes Cênicas. Mas vale ressaltar que esse estudo não pretende ter fim em si mesmo, sugerindo, portanto, outros possíveis olhares a partir dos dados e das provocações acadêmicas aqui levantadas. 
O curso da UDESC, hoje Bacharelado e Licenciatura em Teatro, é a maior referência teatral no contexto universitário catarinense, tanto pelo seu pioneirismo, quanto pela sua evolução. Hoje o Departamento de Artes Cênicas conta com espaço físico próprio e com um Programa de Pós-Graduação em Teatro, ofertando cursos de Mestrado e Doutorado. Dos 17 professores efetivos do curso de graduação, 13 são doutores, 3 doutorandos e 1 mestre, o que dá credibilidade e visibilidade à qualidade de oferta do curso.

\section{UNIVERSIDADE FEDERAL DE SANTA CATARINA - UFSC}

\section{Quadro diagnóstico}

(Informações colhidas na página de apresentação do curso na internet em 2010). INSTITUIÇÃO: Universidade Federal de Santa Catarina NOME DO CURSO: Bacharelado em Artes Cênicas - Habilitação em Teatro TEXTO DE APRESENTAÇÃO DO CURSO:

O curso de Bacharelado em Artes Cênicas - UFSC - Habilitação em Teatro oferece uma formação em três áreas: a dramaturgia, a fim de incentivar a composição de obras e propostas conceituais na elaboração de atos dramáticos; o aprimoramento de atores, para atuarem em diferentes mídias, e a direção teatral, como configuração versátil, autônoma e em contínua mudança de parâmetros. Essas áreas: a dramaturgia, a atuação e a direção compreendem intervenções em três eixos: a teoria, a técnica e a criação. Em suas fases finais, consolidam-se os diversos saberes em projetos de criação e montagem de obras, com vistas à pesquisa nesse campo multidisciplinar, com o objetivo de uma intervenção social direta na formação de público, para a ampliação de repertório cultural e como projeto de vínculo direto em diferentes comunidades.

HABILITAÇÃO: Bacharelado em Artes Cênicas, habilitação em Teatro.

TITULAÇÃO: Bacharel em Artes Cênicas com habilitação em Teatro.

CRIAÇÃO: Resolução no 003/CEG/2007, de 16 de maio de 2007. 
INÍCIO DAS ATIVIDADES: Fevereiro de 2008.

PERÍODO DE CONCLUSÃO DO CURSO: 8 semestres.

CARGA HORÁRIA OBRIGATÓRIA: $2200 \mathrm{~h} / \mathrm{a}$.

VAGAS: 40 vagas anuais.

TURNO: Noturno.

SEMESTRE EM QUE O CURSO É OFERECIDO NO VESTIBULAR: $1^{\circ}$.

LOCAL DE FUNCIONAMENTO: Florianópolis.

A Universidade Federal de Santa Catarina tomou a iniciativa de ofertar um curso superior em Artes Cênicas numa faixa temporal mais tardia se relacionada a outras instituições federais no Brasil. Isso se deve, possivelmente, ao fato de a Universidade do Estado de Santa Catarina ter conquistado o status de monopólio no ensino superior de Teatro público catarinense. A proximidade geográfica das duas instituições fez com que a oferta de cursos de artes ficasse subordinada a uma localidade, a um grupo, a uma esfera social delimitada.

Bakhtin (1998), ao discutir as forças centrípetas e centrífugas, aponta para o fato de que é necessário que as forças enunciativas de ordem centrífuga venham à tona, para que as centrípetas, centralizadoras, dêem espaço a discursos que não venham somente como sugestão de única verdade ou único enunciado possível. Esse movimento abre espaço para situações enunciativas permeadas pela alteridade e heterogeneidade, que permitam o surgimento da diferença, da sugestão e da oportunidade de opção por parte de quem procura ingressar num curso superior em Artes Cênicas.

Assim, é possível compreender que as vozes sociais que circulavam no ensino superior em Artes Cênicas catarinense, e que colocavam à UDESC como única instituição provedora do ensino gratuito em Teatro, foram, aos poucos, acostumando-se com a ideia de um outro curso de mesmo nível, com outra habilitação e com outros objetivos. É por isso que o curso de Bacharelado em Artes 
Cênicas, habilitação em Teatro da UFSC carrega características tão marcadamente diferentes da graduação da UDESC.

A primeira dessas características está relacionada com uma fuga total de qualquer palavra que aproxime o curso de uma licenciatura. No texto de apresentação esse fator é evidente: "O curso de Bacharelado em Artes Cênicas UFSC - Habilitação em Teatro oferece uma formação em três áreas: a dramaturgia, a atuação e a direção." Esse diferencial faz com que o curso se auto-afirme como um propiciador de algo antes inexistente em Florianópolis, isto é, uma opção de formação em Teatro direcionada àqueles acadêmicos que não tem interesse na formação enquanto professores de Teatro, e sim enquanto atores, diretores e dramaturgos.

O curso é também oferecido no período noturno, o que o difere da graduação da UDESC, que é diurna, possibilitando à comunidade o direito de escolha, e facilitando aos que trabalham durante o dia a realização de uma graduação no período da noite. A marca da diferença, em Lopes (2001) é por si só, marca de identidade, porque a diferença só se faz onde processos identitários existam. E essa marca, no caso do curso de Teatro da UFSC, é um sinal enunciativo, percebido no discurso da universidade sobre o novo curso que oferece.

Ao apresentar o curso e falar sobre a formação acadêmica que se pretende atingir, o texto mostra que nas "fases finais, consolidam-se os diversos saberes..." Esse enunciado aponta para o Teatro como um conhecimento que pode ser apreendido, como um conjunto de diversos saberes que podem ser consolidados, no sentido de formação de um sujeito capaz de abarcar uma série de saberes sobre o fazer teatral.

A promessa dos "projetos de criação e montagem de obras, com vistas à pesquisa nesse campo multidisciplinar" sugere um curso totalmente imerso na pesquisa e que por certo propiciará ao acadêmico um descobrir constante, com foco na montagem de espetáculos e na pesquisa multidisciplinar, isto é, com várias visões de mundo advindas de áreas distintas. 
Ainda no campo da perspectiva diferencial nos enunciados sobre o curso, encontra-se o objetivo do curso, que pretende realizar "uma intervenção social direta na formação de público, para a ampliação de repertório cultural e como projeto de vínculo direto em diferentes comunidades." São três desafios apresentados que reafirmam o discurso da diferença, da necessidade de uma nova oferta para uma nova demanda. Discurso este que impulsionou a UDESC a reavaliar sua oferta e também, a partir do mesmo ano de início do curso da UFSC, a oferecer o bacharelado integrado à licenciatura.

O curso da UFSC está sendo ofertado com um corpo docente formado por doutores em sua maioria. A identidade da graduação ainda está sendo construída, pois depende da relação da universidade com o curso, dos acadêmicos que recebe a cada ano e da ação do corpo docente. Apesar de novo, o curso surge como um fortalecimento às Artes Cênicas em Santa Catarina e como um opcional de formação que tende a se erguer e tornar-se referência, dentro dos limites e das possibilidades da formação que proporciona.

\section{UNIVERSIDADE DO OESTE DE SANTA CATARINA - UNOESC}

\section{Quadro diagnóstico}

(Informações colhidas na página de apresentação do curso na internet em 2010). INSTITUIÇÃO: Universidade do Oeste Catarinense.

NOME DO CURSO: Licenciatura em Artes Cênicas.

TEXTO DE APRESENTAÇÃO DO CURSO:

O curso ora proposto tem por objetivo geral formar o profissional de Licenciatura em Artes Cênicas, capacitado a atuar na amplitude desta área de conhecimento, com consciência ética do processo histórico-artístico-pedagógico das linguagens cênicas e teatral no exercício do ensino das artes cênicas, tanto no âmbito formal como em práticas não-formais de ensino.

HABILITAÇÃO: Licenciatura em Artes Cênicas.

TITULAÇÃO: Licenciado em Artes Cênicas.

CRIAÇÃO: RES.97/CONSUN/2007 - 12/09/2007. 
INÍCIO DAS ATIVIDADES: Fevereiro de 2008.

PERÍODO DE CONCLUSÃO DO CURSO: 8 Fases.

CARGA HORÁRIA OBRIGATÓRIA: 2850h/a (sendo 75 em atividades complementares abertas).

VAGAS: 40 vagas anuais para cada campus .

REGIME E TURNO DE OFERTA: O curso poderá ser oferecido em regime regular ou em regime especial, com funcionamento nos períodos diurno e noturno, de acordo com as necessidades observadas, regulamentado em Edital específico do processo seletivo.

SEMESTRE EM QUE O CURSO É OFERECIDO NO VESTIBULAR: $1 \stackrel{\circ}{1}$ LOCAIS DE FUNCIONAMENTO: Joaçaba e São Miguel do Oeste.

O curso de Licenciatura em Artes Cênicas da UNOESC é o mais distante geograficamente da região da grande Florianópolis e do Vale do Itajaí. Ele está localizado no oeste do estado, atendendo a demanda das cidades de São Miguel do Oeste e Joaçaba, como campus centrais onde o curso é oferecido, e com uma área de abrangência que abarca um número grande de municípios circunvizinhos das duas cidades.

O curso teve sua primeira turma com início das atividades no ano de 2008, buscando "formar o profissional de Licenciatura", ou seja, a formação do professor de Teatro. Biange Cabral, ao discutir a relação entre Bacharelado e Licenciatura na área teatral, defende que o foco dos cursos, em ambas as habilitações, precisa estar nas oportunidades que os acadêmicos encontram durante a vivência na universidade, de aliar seus conhecimentos a experiências práticas na comunidade.

O texto que apresenta o curso aponta para essa preocupação, quando defende que a graduação pretende que seus egressos estejam aptos a atuar "tanto no âmbito formal como em práticas não-formais de ensino". Esse caráter múltiplo, que sinaliza vários sentidos e locais destinados ao ato de ensinar, sugere que o profissional formado por este curso saberá lidar com situações formais, relacionadas 
principalmente às escolas e ao ensino de arte nesse contexto, e com situações não formais, como empresas, órgãos privados e cursos livres.

Sobre a questão da relação da universidade com outros meios, Cabral (2009) ainda enuncia que:

A dinâmica social brasileira e nossos problemas de educação e ensino, afastam o aluno da profissão, pois a universidade não o tem preparado para enfrentar esta realidade; a teoria tem se mostrado muito aquém, e usualmente impotente, para enfrentar os graves problemas do ensino básico público, como violência, drogas, e mesmo prostituição. Para enfrentá-los ou pelo menos se tentar formas de enfrentamento, é urgente uma maior interação universidade-comunidade-escola, durante todas as fases da licenciatura, e eu diria, também do bacharelado.

O curso de Artes Cênicas da UNOESC propõe a formação de um sujeito que, além de usar seus conhecimentos a favor da sociedade, esteja "capacitado a atuar na amplitude desta área de conhecimento, com consciência ética do processo histórico-artístico-pedagógico das linguagens cênicas e teatral”. Ao unir história, arte e pedagogia, a concepção de ensino dessa graduação mostra-se multidisciplinar, da mesma maneira que os outros cursos apresentados até aqui. Esse é um dado significativo, pois sinaliza para o ensino do Teatro na universidade como uma possibilidade de educação multirreferencial, que agrega várias áreas de conhecimento, em prol da formação de um sujeito apto a exercer sua profissão a partir de diferentes modalidades (atuação, interpretação, direção, cenografia, professorado, etc.).

A implantação do curso sinaliza também para um pronto atendimento às necessidades da comunidade ao propor possibilidades de alteração em seu turno e regime de oferta: "O curso poderá ser oferecido em regime regular ou em regime especial, com funcionamento nos períodos diurno e noturno, de acordo com as necessidades observadas, regulamentado em Edital específico do processo seletivo (grifo meu)". Observo, a partir desse enunciado, que o curso, por estar em uma fase inicial e por integrar uma universidade de caráter privado (paga), mostra-se aberto às adaptações recorrentes da procura pela graduação, o que me faz concordar com 
Bakhtin, para quem a situação e o meio social determinam por completo a forma e o estilo da enunciação.

Da mesma forma que um sujeito se molda às diferentes situações de determinado contexto enunciativo, o discurso que permeia a Licenciatura em Artes Cênicas da UNOESC aponta para um curso de graduação que vai aos poucos se adaptando à esfera social de sua realidade, preocupado com o impacto regional e atendimento da demanda pelo ensino de Teatro na região oeste do estado de Santa Catarina.

\section{UNIVERSIDADE REGIONAL DE BLUMENAU - FURB}

\section{Quadro diagnóstico}

(Informações colhidas na página de apresentação do curso na internet em 2010). INSTITUIÇÃO: Universidade Regional de Blumenau.

NOME DO CURSO: Artes, Bacharelado em Teatro-Interpretação.

TEXTO DE APRESENTAÇÃO DO CURSO:

O curso de Artes da FURB é dividido em Licenciatura em Música, em que o estudante é preparado para ministrar aulas de música; também há possibilidade de seguir por Licenciatura em Artes Visuais, formando professores para as áreas de pintura, escultura, cerâmica, gravura, entre outras; por último, há ainda o Bacharelado em Teatro, com Habilitação em Interpretação, curso único no Estado, preparando o estudante a exercer a profissão de ator.

O Bacharelado em Teatro, com ênfase em Interpretação, prepara atores e profissionais para atuar em diversas áreas das Artes Cênicas, na produção teatral e como agentes culturais, suscitando a criação artística, a reflexão, a fruição e a consequente transformação da sociedade. Além de participar de atividades e projetos de pesquisa e extensão na Universidade e na comunidade em geral, os profissionais da área de Artes estão igualmente aptos para atuar em espaços culturais como museus, galerias, fundações, conservatórios, teatros, grupos e escolas livres de ensino informal. 
HABILITAÇÃO: Bacharelado em Teatro-Interpretação.

TITULAÇÃO: Bacharel em Teatro-Interpretação.

CRIAÇÃO: Par.-CEPE 082 de 17/5/1994.

INÍCIO DAS ATIVIDADES: 20/02/1995.

ÚLTIMA ALTERAÇÃO CURRICULAR: Parecer 65/2005 de 12 de abril de 2005.

PERÍODO DE CONCLUSÃO DO CURSO: 8 semestres.

CARGA HORÁRIA OBRIGATÓRIA: 3168h/a (sendo 216 em Atividades

Acadêmico-Científico-Culturais - AACC).

VAGAS: 15 vagas anuais.

TURNO: Noturno.

SEMESTRE EM QUE O CURSO É OFERECIDO NO VESTIBULAR: $1 \stackrel{\text {. }}{\text {. }}$ LOCAL DE FUNCIONAMENTO: Blumenau.

O discurso que apresenta o curso superior em Teatro da FURB tem um caráter exclusivista, ao enfatizar que o Bacharelado em Teatro, com Habilitação em Interpretação, é um "curso único no Estado, preparando o estudante a exercer a profissão de ator".

Desde 1995, a FURB oferece o Bacharelado na área de Artes Cênicas como única opção no território catarinense com o foco na formação de atores (Interpretação). A Universidade Regional de Blumenau é a segunda do estado a oferecer um curso na área de Teatro, e seu diferencial está justamente na oferta do bacharelado, visto que a UDESC, como referenciei anteriormente, só passa a dimensionar essa habilitação a partir do ano de 2008, juntamente com o surgimento do curso superior de Teatro da UFSC.

Além do título de bacharel, até o ano de 2005 a FURB oferecia aos acadêmicos egressos a oportunidade de obter a licenciatura, com disciplinas pedagógicas específicas e com uma complementação possível em outros cursos da universidade, sendo o primeiro curso de Santa Catarina a possibilitar uma dupla titulação em Teatro. Outra peculiaridade dessa graduação está no fato de possuir 
sua ênfase de formação na Interpretação, isto é, o diplomado sai com uma titulação em uma área específica do Teatro: a atuação.

Esses fatores diferenciais colocam o curso de Teatro-Interpretação da FURB em lugar que, em seu pioneirismo, se assemelha a outras graduações no sul do país, que pretendem que seus egressos saiam da universidade com titulações direcionadas a uma área específica do fazer teatral.

Porém, mesmo com uma formação mais diretiva e focada em uma área de concentração, o curso não desconsidera o fato de que as Artes Cênicas proporcionam um amplo leque de possibilidade de exercício da profissão, afirmar que a graduação prepara atores e profissionais para atuar em diversas áreas das Artes Cênicas (grifo meu). Esse discurso também aproxima os objetivos do curso aos propósitos existenciais das outras universidades que oferecem a graduação em Teatro ou Artes Cênicas. O fato de todas elas apontarem para a amplitude da área, os diversos saberes vivenciados com os acadêmicos e as inúmeras possibilidades de atuação do egresso, possibilita o indício de uma regularidade enunciativa presente no ensino superior em Artes Cênicas catarinense: a multidisciplinaridade que circula nos cursos de graduação em Teatro.

Em todos os discursos sobre as graduações, é notável que as universidades consideram o Teatro como uma área de conhecimento que agrega diversos saberes e possibilidades, alcançando sua plena realização no âmbito da multiplicidade de sentidos para o fazer teatral. Esses discursos permitem que eu concorde com Bakhtin (2006), em sua defesa de uma dinâmica de linguagem constituída pela heteroglossia, inclusive na produção do conhecimento. Para o autor, um enunciado não tem fim em si mesmo, pois possibilita diferentes oportunidades responsivas em um contexto enunciativo. No contexto acadêmico do ensino superior em Teatro catarinense, os discursos de apresentação das graduações são, ao mesmo tempo, semelhantes em sua materialidade, ao concordarem entre si que a multidisciplinaridade de saberes os constitui, e heterogêneos ao sinalizar inúmeros sentidos para a prática cênica e distintas possibilidades de identidade formativa dos egressos de cada curso. 
O curso de Teatro-Interpretação da FURB, também tem uma preocupação em aproximar a Universidade da comunidade, quando o texto de apresentação da graduação enuncia que: "Além de participar de atividades e projetos de pesquisa e extensão na Universidade e na comunidade em geral" os acadêmicos também estarão aptos a "atuar em espaços culturais como museus, galerias, fundações, conservatórios, teatros, grupos e escolas livres de ensino informal". Esse discurso sugere que o curso possibilite a participação do acadêmico em projetos de integração com a universidade (pesquisa e extensão), e que existe um compromisso por parte do egresso com a comunidade, apontando, da mesma maneira que 0 curso da UNOESC, para a inserção e impacto regionais.

$\mathrm{O}$ foco em atender os anseios da comunidade, e, por consequência, em um contexto geográfico de caráter regional, distingue as graduações oferecidas nessas duas instituições, FURB e UNOESC, das ofertadas na capital catarinense, pela UDESC e pela UFSC. Enquanto as duas primeiras direcionam os seus cursos para um impacto de ordem local, as outras apresentam discursos marcadamente voltados para um trabalho destinado a atender uma demanda de cunho estadual. Isso se deve ao fato de os cursos de teatro de Florianópolis serem ofertados por instituições públicas e gratuitas, em campus que tem por tradição histórica receber acadêmicos de diversas regiões do estado e também do país.

Já o curso da FURB, oferecido em Blumenau, recebe, em sua grande maioria, acadêmicos advindos da região do Vale do Itajaí e municípios circunvizinhos. Da mesma forma o curso oferecido pela UNOESC, como apresentado anteriormente, é o único do oeste do estado e tem interesse em um público formado por acadêmicos que moram nos municípios próximos dos seus locais de oferta: Joaçaba e São Miguel do Oeste. Ambos os cursos, tanto o da FURB como o da UNOESC, são frequentados por alunos pagantes, o que também os distingue dos demais. 


\section{CONCLUSÕES}

Esse estudo contribui para um mapeamento do ensino superior em Teatro em Santa Catarina, a partir de uma perspectiva enunciativa de análise, que considera os discursos institucionais das universidades sobre suas graduações. A conclusão que melhor cabe nestas linhas é a de que a evolução do Teatro no ensino superior catarinense está em processo de alteridade constante.

Há apontamentos para sentidos de história e tradição, a partir da graduação em Teatro da UDESC e sentidos de inovação e contemporaneidade a partir da proposta de graduação da UFSC. Essas duas instituições abarcam um corpo discente estadual e nacional. Já a FURB e a UNOESC sinalizam em seus discursos, um sentido de compromisso com comunidades locais, com graduações que parecem adaptadas às realidades locais.

Há uma lacuna em algumas regiões geográficas do estado, as quais não possuem cursos de graduação na área do Teatro.

Ambas as graduações existentes sinalizam um comprometimento com uma formação ampla e não reducionista, pois compreendem o Teatro como um campo multidisciplinar e com diferentes possibilidades de exercício da profissão. Também não há sentidos dicotômicos entre licenciatura e bacharelado, pelo menos na compreensão de que as habilitações são, antes de distintas, complementares entre si. Há a necessidade do bacharelado e também da licenciatura, e isso se confirma no curso da UDESC, que possui as duas habilitações, e no curso da FURB, que ofereceu já licenciatura como complementação ao bacharelado.

Investigar esses movimentos transitórios e as formas como as universidades vão se adaptando aos momentos históricos, torna-se um importante fator de compreensão da própria história do Teatro. O estudo possibilitou um olhar dialógico para o ensino superior catarinense na área de Teatro, a partir dos estudos enunciativos, em uma perspectiva de linguagem que propõe uma metodologia de análise que possa ultrapassar os tradicionais mapeamentos, dando voz à questão dos sentidos como possibilidade de escuta investigativa em Teatro. 


\section{REFERÊNCIAS BIBLIOGRÁFICAS}

ALMEIDA, V. O Teatro como Extensão Universitária em Santa Catarina. Dissertação de Mestrado (Programa de Pós-Graduação em Teatro). Florianópolis: UDESC, 2006.

BAKHTIN, M. Estética da Criação Verbal. 4. ed. São Paulo: Ed Martins Fontes, 2006.

Questões de literatura e estética. A teoria do romance. 4. ed. São Paulo: UNESP, 1998.

CABRAL, B. A relação bacharelado-licenciatura e a natureza da prática pedagógica em artes. In: Arte Online - periódico online de artes. Volume 1. Florianópolis.Disponível em: http://www.ceart.udesc.br/Revista_Arte_Online. Acesso em : 15/06/2009.

HAWERROTH, Jolmar L. A Expansão do Ensino Superior nas Universidades do Sistema Fundacional Catarinense. Florianópolis: Insular, 1999.

LOPES, L. Discursos de identidade em sala de aula de L1: a construção da diferença. In: SIGNORINI,I. Linguagem e identidade: elementos para uma discussão no campo aplicado. Campinas: Mercado de Letras/FAPESP, 1998. p. 303-330.

LORGUS, A. O TCC como reflexo do letramento acadêmico dos alunos de Graduação em Design da Universidade Regional de Blumenau. Dissertação de Mestrado (Programa de Pós-Graduação em Educação). Blumenau: FURB, 2009. 